DOI https://doi.org/10.30525/978-9934-26-110-7-30

\title{
ЧАСТОТНІ МОДЕЛІ РЕЧЕНЬ НА 4-6 СЛІВ ДЛЯ МОРФЕМИ «给»
}

\author{
Козоріз О. П. \\ кандидат філологічних наук, \\ асистент кафедри мов і літератур Далекого Сходу \\ та Південно-Східної Азії \\ Інституту філології \\ Київький національний університет імені Тараса Шевченка \\ м. Київ, Украӥна
}

Для досягнення мети дослідження слід виконати такі завдання: 1. Визначити критерії та відібрати матеріал для дослідження. 2. Запропонувати методику та виділити найчастотніші моделі речень на 4-6 слів, в тому числі з морфемою 给. 3. Створити програму автоматичного тегування, виокремлення моделей, створення списку частотних моделей речень. 4. Перевірити ефективність роботи програми на паралельних перекладах китайської та англійської мов.

Першим кроком шляхом завантаження 3 сайту QuWord [11] було створено китайсько-англійський паралельний корпус на 920000 пар речень [1]. На його основі відібрані за англійською частиною речення 3 довжинами від 4 до 6 слів для морфеми «给». Відбір речень саме цієї довжини зумовлений їхньою частотністю у розмовній мові, складністю для перекладу системами машинного перекладу, теоретичною можливістю їхньої систематизації (через відносно невелику довжину). Морфема «给» була обрана через наявність у неї граматичної омонімії, аби перевірити якість роботи програм. Відбір проводився регулярними виразами: ${ }^{\wedge} .|t| w *|\mathrm{~W}| \mathrm{w}^{*}|\mathrm{~W}| \mathrm{w} *|\mathrm{~W}| \mathrm{w} * \mid \mathrm{W} \$-4$ слова і т. д. Англійська мова використовувалися оскільки можна однозначно визначити межі слова. Всього було відібрано 1105 пар речень, 4 слова - 100 речень, 5 слів - 370 речень, 6 слів - 635 речень. Порівняльні графіки кількості слів у реченні для китайської та англійської мов можна бачити на Рис. 1. Китайські речення виявилися дещо довшими за англійські, це пов'язано в тому числі з функціями структурних елементів речення, які може виконувати зазначена морфема, утворювати пасив, прийменникові словосполучення тощо. 


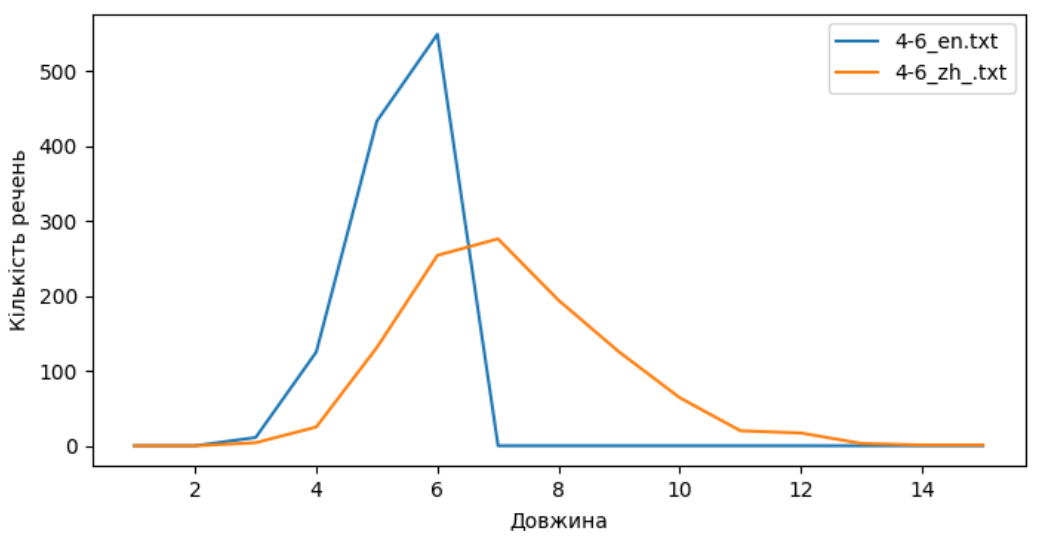

Рис. 1. Порівняльний графік кількості слів у реченні для китайської та англійської мов

Тегування англійської частини було проведене за допомогою Free CLAWS web tagger [5]. Тут мається на увазі POS тегування - (Part-ofspeech) частиномовна розмітка, яка також називається граматичним тегуванням, $\epsilon$ поширеною формою анотації корпусу, була першою формою анотації розробленою в UCREL Ланкастера, за різними даними досягає точності 93-97\%.

У школах вивчають 9 частин мови, однак категорій та підкатегорій можна виділяти набагато більше. Ми користувалися UCREL CLAWS5 Tagset, що включає 62 категорії слів, для дієслів англійської мови тут пропонується 24 категорії, для іменників та займенників - 4 категорії на кожну частину мови [9].

Після тегування 1105 речень, див. Табл. 1, загалом отримали 872 моделі речень, що складає 79\%: 4 слова - 79 моделей речень, 5 слів -285 моделей речень, 6 слів - 512 моделей речень. Можливо через занадто широку граматичну категоризацію англійської мови, моделей речень на 4-6 лише для одного слова виявилося майже $80 \%$ від початкової кількості речень.

Таблиця 1

\section{Ілюстративна таблиця тегованого англійського тексту} та відповідні моделі речень

\begin{tabular}{|c|c|c|}
\hline $\begin{array}{c}\text { Англійська } \\
\text { мова }\end{array}$ & Тегований англійський текст & Моделі речень \\
\hline $\begin{array}{c}\text { Give me a kiss! } \\
\text { Who'd you call? }\end{array}$ & Give_VVB me_PNP a_AT0 & VVB PNP AT0 NN1 \\
\hline
\end{tabular}




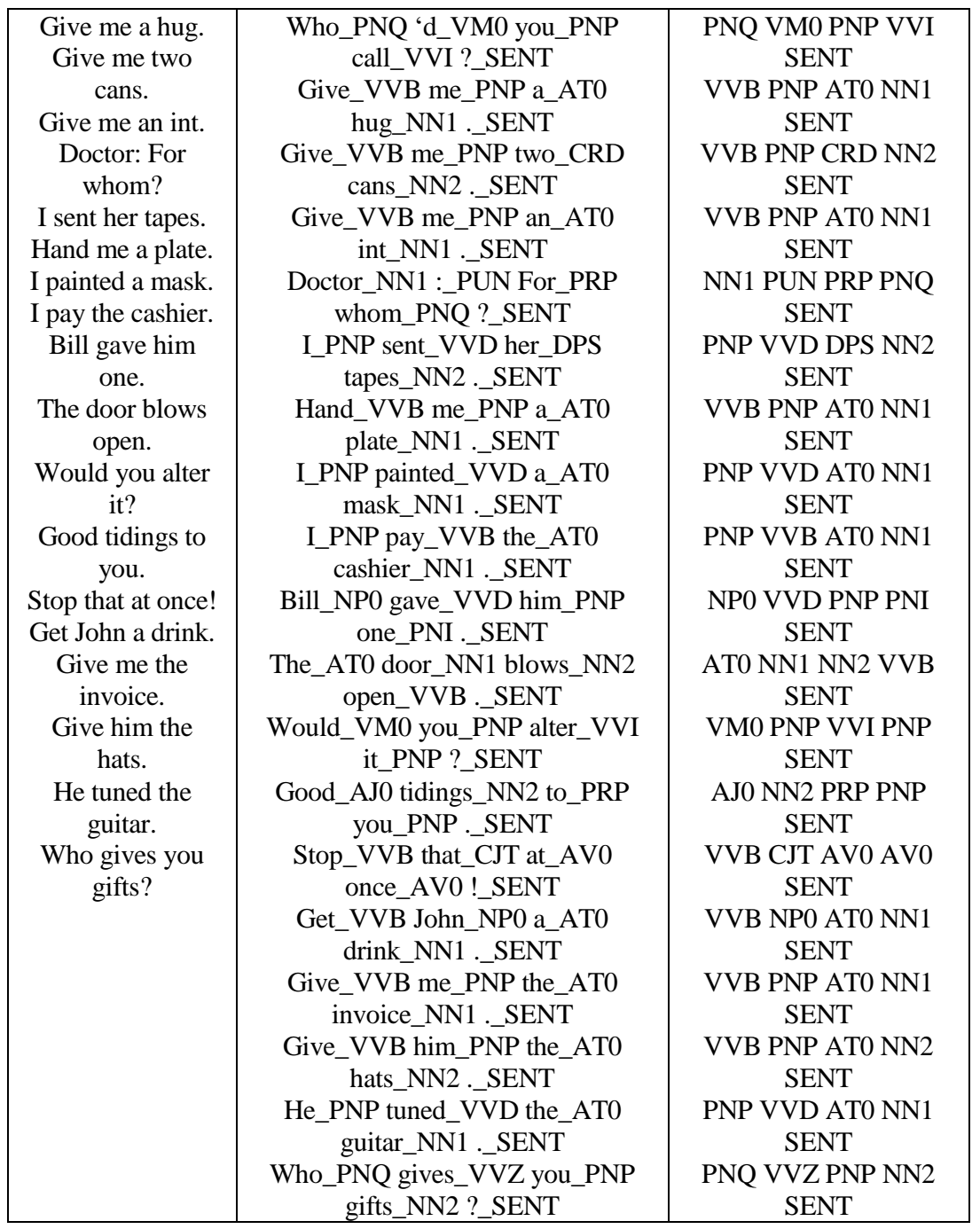

Для китайської мови спочатку ми провели тегування за допомогою сайту 汉语分词和词性自动标注 [10], що містить 35 граматичних категорій слів: 11 - іменники, 4 - дієслова тощо. Після тегування 1105 речень, див. Табл. 2, загалом отримали 1027 моделі речень, що складає $93 \%$. 
Тут виникає багато запитань як щодо алгоритму розбивки тексту на слова, так і до безпосередньо тегування: ієрогліф 给 скрізь позначено як «р» - тобто прийменник, хоча він може бути і дієсловом, 一个 - це одне слово, що позначено як «/r « - тобто займенник, у іншому випадку ієрогліф - - це числівник «/m», з чим ми згодні, а ієрогліф 张 - це прізвище «/nhf», хоча і є категорія «q» - рахівні слова, що була б доречна у цьому випадку. 约/v 翰/x - ім'я поділено на окремі частини.

Таблиця 2

\section{Ілюстративна таблиця тегованого китайського тексту}

та відповідні моделі речень від сайту 汉语分词和词性自动标注

\begin{tabular}{|c|c|c|c|}
\hline № & Китайська мова & $\begin{array}{c}\text { Тегований китайський } \\
\text { текст }\end{array}$ & Моделі речень \\
\hline $\begin{array}{l}1 \\
2 \\
3 \\
4 \\
5 \\
6 \\
7 \\
8 \\
9 \\
10 \\
11 \\
12 \\
13 \\
14 \\
15 \\
16 \\
17 \\
18 \\
19 \\
20\end{array}$ & $\begin{array}{c}\text { 给我个吻 } \\
\text { 给谁打过电话? } \\
\text { 给我一个拥抱吧 } \\
\text { 给我来两罐 } \\
\text { 给我一个int数 } \\
\text { 医生 : 给谁的 } \\
\text { 我给她寄磁带 } \\
\text { 递给我一个盘子 } \\
\text { 我给面具上色 } \\
\text { 我付钱给收银 } \\
\text { 比尔给了他一张。 } \\
\text { 门给吹开了 } \\
\text { 您能给锁边吗? } \\
\text { 好消息给你 } \\
\text { 马上给我停下来 } \\
\text { 给约翰拿杯饮料来 } \\
\text { 把发票给我。 } \\
\text { 把这些帽子送给他 } \\
\text { 他给吉他定弦。 } \\
\text { 谁给你的礼物? }\end{array}$ & 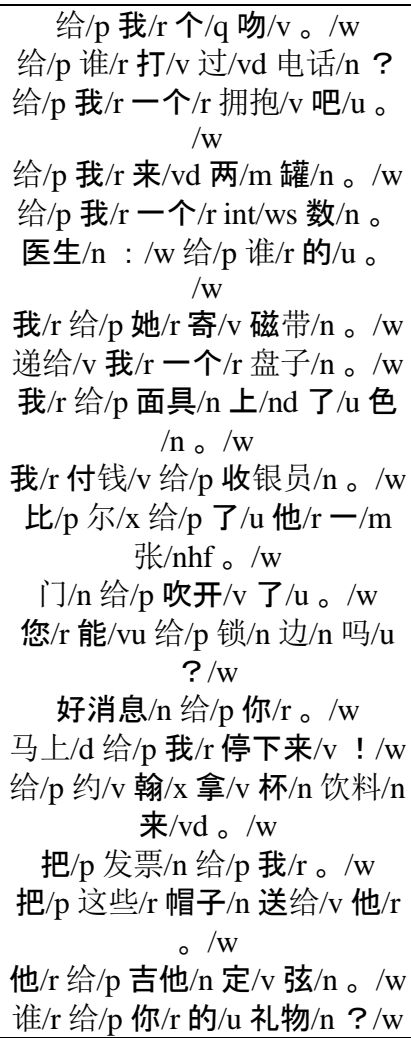 & $\begin{array}{c}\text { prqvw } \\
\text { prvvdnw } \\
\text { prrvuw } \\
\text { prvdmnw } \\
\text { prrws nw } \\
\text { nwpruw } \\
\text { rprvnw } \\
\text { vrrnw } \\
\text { rpndunw } \\
\text { rvpnw } \\
\text { pxpurmnhw } \\
\text { npvuw } \\
\text { r vupnuw } \\
\text { nprw } \\
\text { dprvw } \\
\text { p v x nnvd } \\
\text { pnprw } \\
\text { prnvrw } \\
\text { rpnvnw } \\
\text { rprunw }\end{array}$ \\
\hline
\end{tabular}


Інша програма тегування китайського тексту SegmentAnt [12], містить 24 граматичних маркування слів. Після тегування 1105 речень, див. Табл. 3, загалом отримали 1015 моделей речень, що складає 91\%. Тут також виникають питання до 给_p, яке скрізь тегується прийменником, дивні поєднання словосполучень 我个_r, 一个_m, 一张_m, натомість розрізняє імена - 约翰_nrt. Тобто довіряти такому тегуванню можна досить відносно, а отже отримані моделі речень будуть мати великий відсоток помилок (біля 10\%). Визначення частин мови для таких морфем як 给, 在, 到 потребує досить серйозного алгоритму.

Таблиця 3

Ілюстративна таблиця тегованого китайського тексту виконаного програмою SegmentAnt та відповідні моделі речень

\begin{tabular}{|c|c|c|c|}
\hline № & Китайська мова & Тегований китайський текст & $\begin{array}{l}\text { Моделі } \\
\text { речень }\end{array}$ \\
\hline $\begin{array}{l}1 \\
2 \\
3 \\
4 \\
5 \\
6 \\
7 \\
8 \\
9 \\
10 \\
11 \\
12 \\
13 \\
14 \\
15 \\
16 \\
17 \\
18 \\
19 \\
20\end{array}$ & $\begin{array}{c}\text { 给我个吻。 } \\
\text { 给谁打过电话? } \\
\text { 给我一个拥抱吧 } \\
\text { 给我来两罐。 } \\
\text { 给我一个int数。 } \\
\text { 医生 : 给谁的。 } \\
\text { 我给她寄磁带。 } \\
\text { 递给我一个盘子 } \\
\text { 我给面具上色 } \\
\text { 我付钱给收银员 } \\
\text { 比尔给了他一张 } \\
\text { 门给吹开了。 } \\
\text { 您能给锁边吗? } \\
\text { 好消息给你。 } \\
\text { 马上给我停下来 } \\
\text { 给约翰拿杯饮料 } \\
\text { 来。 } \\
\text { 把发票给我。 } \\
\text { 把这些帽子送给 } \\
\text { 他。 } \\
\text { 他给吉他定弦。 } \\
\text { 谁给你的礼物? }\end{array}$ & 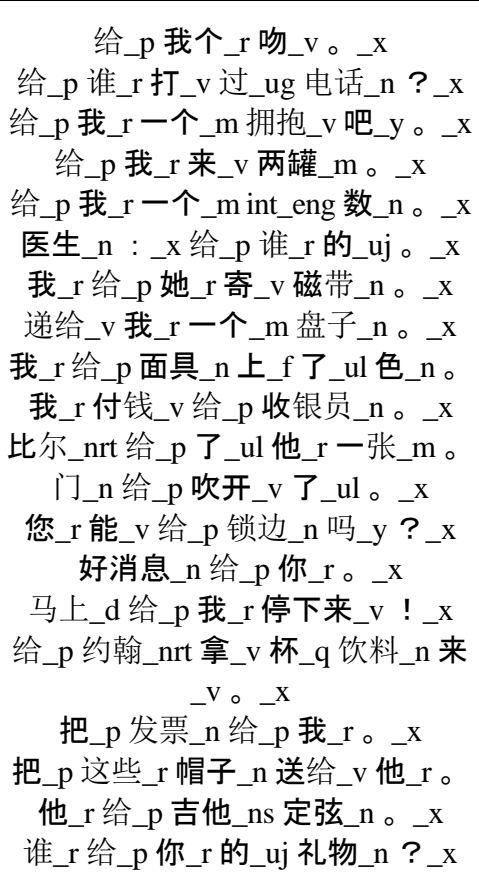 & 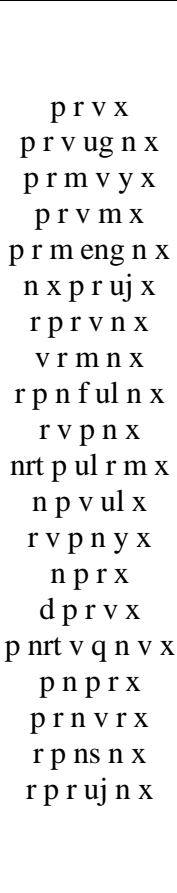 \\
\hline
\end{tabular}


Після алфавітного сортування списку моделей речень, регулярним виразом типу «(^.*\$) $\ln (\backslash 1) \ln (\backslash 1) \backslash n . .$. вручну було виділено 15 найчастотніших моделей китайських речень 3 морфемою «给» на 4-6 слів, див. Табл. 4, які розташовані у порядку спадання частотності. Для пошуку моделей речень серед тегованого тексту можна користуватися регулярним виразом типу: $\left[{ }^{\wedge}\right]^{*}{ }_{-}\left[{ }^{\wedge}\right]^{*}{ }_{-}\left[^{\wedge}\right]^{*}{ }_{-}\left[^{\wedge}{ }^{\wedge}\right]_{-}^{*} \mathrm{v}\left[{ }^{\wedge}\right]^{*}{ }_{-} \mathrm{ul}\left[{ }^{\wedge}\right]^{*}{ }_{-} \mathrm{r}\left[{ }^{\wedge}\right]^{*}{ }_{-}$х. Через недоліки роботи програми тегування китайського тексту, хоча ми і змогли виявити найчастотніші моделі речень, моделі 7-10 та 14 виглядають сумнівно з точки зору граматичної приналежності «给» до прийменника, але через невелику їх кількість піддаються коригуванню та можуть бути використані у навчальному процесі.

Таблиця 4

Частотні моделі китайських речень з морфемою 给

\begin{tabular}{|c|c|c|}
\hline & $\begin{array}{c}\text { Модель } \\
\text { речення }\end{array}$ & Приклади вживання \\
\hline & rvrmnx & $\begin{array}{c}\text { 他_r 借给_v 我_r 一辆_m 自行车_n。_x 他_r 送 } \\
\text { 给_v 她_r 许多_m 礼物_n。_x }\end{array}$ \\
\hline & rprvul mnx & $\begin{array}{l}\text { 她_r 给_p 我_r 烤_v 了_ul 一块_m 牛排_n。 他 } \\
\text { _r 给_p 我_r 带来_v了_ul一些_m 糖果_n。 }\end{array}$ \\
\hline & $\mathrm{npvulx}$ & $\begin{array}{l}\text { 门_n 给_p 吹开_v了_ul。_x 下水道_n 给_p 堵 } \\
\text { 住_v 了_ul。肿瘤_n 给_p 切除_v 了_ul。_- }\end{array}$ \\
\hline & $\mathrm{rpulrmnx}$ & $\begin{array}{l}\text { 他_r 给_p 了_ul 我_r - 点_m 墨水_ns。_x 他_r } \\
\text { 给_p 了_ul 我_r 些_m 水果_n。_x } \\
\text { 他们_r 给_p 了_ul 我_r 许多_m 礼物_n。_x }\end{array}$ \\
\hline & rpnvex & $\begin{array}{c}\text { 他_r 把_p 小刀_n 借给_v 我_r o_n 他_r 把_p 球 } \\
\text { _n 扔给_v 我_r o_x }\end{array}$ \\
\hline & $\mathrm{rpnvulrx}$ & $\begin{array}{c}\text { 她_r 把_p 钱_n 借给_v了_ul 我_ro_x 我_r 把_p } \\
\text { 钥匙_n 扔给_v 了_ul 他_r 。_X }\end{array}$ \\
\hline & rprujnvrul $x$ & 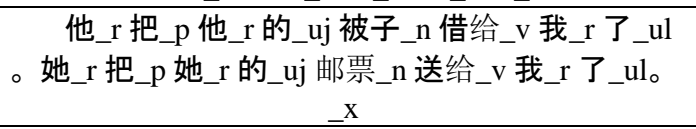 \\
\hline & $\mathrm{npnnx}$ & $\begin{array}{c}\text { 蜜蜂_n 给_p 果树_n 传粉_n。_x 大人_n 给_p } \\
\text { 小孩_n 红包_n。_x }\end{array}$ \\
\hline & $\operatorname{prmnx}$ & $\begin{array}{c}\text { 给_p 我_r 一把_m 螺丝刀卫_n。_x 给_p 我_r 一些 } \\
\text { _m 自主权_n。_x }\end{array}$ \\
\hline 0 & $\mathrm{vprmnx}$ & $\begin{array}{c}\text { 请_v 给_p 我_r 一些_m 餐巾纸_n。_x 请_v 给 } \\
\text { pp 他_r 一些_m 瓶子_n。_x }\end{array}$ \\
\hline & rdpnvax & 他_r 必须_d 给_p 锅炉_n 加_v 燃料_n。_x 她_r \\
\hline
\end{tabular}




\begin{tabular}{|c|c|c|}
\hline 1 & & 曾_d 把_p 房间_ $\mathrm{n}$ 租给_v 大学生_n 。_x \\
\hline 2 & r p n v rul x & $\begin{array}{c}\text { 他_r 把_p 流感_n 传给_v 我_r 了_ul 。_x 我_r } \\
\text { 把_p 自行车_n 借给_v 他_r 了_ul 。_x }\end{array}$ \\
\hline 3 & rpnvugnyx & $\begin{array}{l}\text { 你_r 给_p 狗_n 打_v 过_ug 虫_n 吗_y? } \mathrm{x} \text { 你_r } \\
\text { 给_p 奶牛_n 挤_v过_ug 奶_n 吗_y ? _x }\end{array}$ \\
\hline 4 & r prm nx & $\begin{array}{c}\text { 他_r 给_p 她_r 一个_m 苹果_n。_x 我_r 给_p } \\
\text { 你_r 四分_m 钱_n。_x }\end{array}$ \\
\hline 5 & r prujnvrx & $\begin{array}{l}\text { 他_r 把_p 他_r 的_uj 财产_n 让给_v 我_r o _x } \\
\text { 他_r 把_p 他_r 的_uj 钱_n 借给_v 她_r o_x }\end{array}$ \\
\hline
\end{tabular}

Щоб автоматизувати зазначений процес, завдяки бібліотекам Jieba [6] ми розробили програму на мові Python, що створює список усіх моделей речень корпусу китайського тексту:

import jieba

import jieba.posseg as pseg

import re

with open('4-6_zh.txt', 'rt', encoding='utf-8') as f0:

$$
\mathrm{s}=\mathrm{f} 0 \cdot \operatorname{read}()
$$

words $=$ pseg.cut $(\mathrm{s})$

with open('teg_text.txt', 'wt', encoding='utf-8') as f1:

for word, flag in words:

$$
\begin{aligned}
& \mathrm{s} 2=\left(' \% \mathrm{~s}_{-} \% \mathrm{~s} \text { ' } \%\right. \text { (word, flag) } \\
& \text { print(s2, file=f1, end=' ') }
\end{aligned}
$$

with open('teg_text.txt', 'rt', encoding='utf-8') as f2:

with open('teg_text_models.txt', 'wt', encoding='utf-8') as f3:

$$
\begin{aligned}
& \mathrm{s} 2=\mathrm{f} 2 \cdot \operatorname{read}() \\
& \mathrm{s} 2=\operatorname{re} . \operatorname{sub}\left(\mathrm{r} ’ \_\mathrm{x}\right. \text { ', “, s2) } \\
& \mathrm{s} 2=\operatorname{re} \cdot \operatorname{sub}\left(\mathrm{r}^{\prime \wedge}\left[\wedge^{\wedge} \backslash\right]_{+},{ }^{\prime},{ }^{\prime}, \mathrm{s} 2\right. \text {, flags=re.MULTILINE) }
\end{aligned}
$$

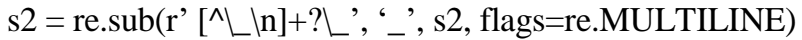

$$
\begin{aligned}
& \text { frequency }=\{\} \\
& \text { match_pattern } \quad=\quad \text { re.findall }\left(r^{\prime}|b .+| b^{\prime}, \quad s 2\right. \text {, }
\end{aligned}
$$

flags=re.MULTILINE)

for word in match_pattern:

count $=$ frequency.get $($ word, 0$)$

frequency[word $]=$ count +1

list_d = list(frequency.items())\#сортировка по значению

list_d.sort(key=lambda i: i[1], reverse=True)

for $\mathrm{i}$ in list_d:

$$
\operatorname{print}(\mathrm{i}[0], ' \mathrm{t} \text { ', i[1], file=f3) }
$$


Результати роботи програми можна переглянути у Табл. 5., де зазначені моделі китайських речень 3 морфемою «给» та частотність їх вживання в автоматичному режимі.

Таблиця 5

\section{Частотні моделі китайських речень 3 морфемою «给» отримані автоматично}

\begin{tabular}{|c|c|c|c|c|c|}
\hline & Модель речення & $\begin{array}{l}\text { частотн } \\
\text { ість } \\
\end{array}$ & & $\begin{array}{c}\text { Модель } \\
\text { речення }\end{array}$ & $\begin{array}{l}\text { частотн } \\
\text { ість }\end{array}$ \\
\hline & r_v_r_m_n & 9 & 1 & r_p_r_m_n & 3 \\
\hline & r_p_r_v_ul_m_n & 7 & 2 & $\begin{array}{c}\text { r_p_n_v_ug } \\
\text { n__y }\end{array}$ & 3 \\
\hline & n_p_v_ul & 4 & 3 & n_p_n_n & 3 \\
\hline & r_p_ul_r_m_n & 4 & 4 & $\begin{array}{c}\text { r_p_r_uj_n_ } \\
\text { v_r }\end{array}$ & 3 \\
\hline & r_p_n_v_r & 4 & 5 & r_d_p_n_v & 3 \\
\hline & r_p_n_v_ul_r & 4 & 6 & r_p_r_v_n & 2 \\
\hline & r_p_r_uj_n_v_r_ul & 4 & 7 & r_p_n_f_ul_ & 2 \\
\hline & v_p_r_m_n & 3 & 8 & p_r_n_v_r & 2 \\
\hline & p_r_m_n & 3 & 9 & p_n_v_r & 2 \\
\hline 0 & r_p_n_v_r_ul & 3 & 0 & v_m_n_p_r & 2 \\
\hline
\end{tabular}

Аби перевірити висновки щодо кількісних характеристик моделей речень не для конкретного слова, було проведено ще один експеримент. Iз зазначеного вище китайсько-англійського паралельного корпусу на 920000 пар речень за англійською частиною відібрано речення лише із 4 слів і побудовано відповідні моделі. Усього виявилося 13000 речень із 4 слів, після тегування отримано близько 4200 моделей речень, що складає $32 \%$. Тобто практично можна скоротити кількість моделей на дві третини відносно початкової кількості речень.

Після сортування списку моделей речень, регулярним виразом вручну за попередньо описаною технологію було виділено 20 найчастотніших моделей речень англійської мови на 4 слова, див. Табл. 6, розташовані у порядку спадання частотності. 
Таблиця 6

Частотні моделі англійських речень на 4 слова

\begin{tabular}{|c|c|c|c|c|}
\hline № & Кіль- & Модель & \multicolumn{2}{|c|}{ Приклади вживання } \\
\hline 1 & 185 & $\begin{array}{c}\text { PNP VVD AT0 } \\
\text { NN1 }\end{array}$ & $\begin{array}{l}\text { I_PNP got_VVD } \\
\text { the_AT0 flu_NN1. }\end{array}$ & $\begin{array}{l}\text { I_PNP dreamed_VVD } \\
\text { a_AT0 crocodile_NN1. }\end{array}$ \\
\hline 2 & 160 & $\begin{array}{c}\text { PNP VVD DPS } \\
\text { NN1 }\end{array}$ & $\begin{array}{c}\text { I_PNP } \\
\text { bumped_VVD } \\
\text { my_DPS head_NN1 }\end{array}$ & $\begin{array}{l}\text { I_PNP blared_VVD } \\
\text { my_DPS horn_NN1 . }\end{array}$ \\
\hline 3 & 124 & $\begin{array}{c}\text { PNP VVD PRP } \\
\text { NN1 }\end{array}$ & $\begin{array}{c}\text { They_PNP } \\
\text { went_VVD by_PRP } \\
\text { ship_NN1. }\end{array}$ & $\begin{array}{l}\text { We_PNP woke_VVD } \\
\text { at_PRP dawn_NN1. }\end{array}$ \\
\hline 4 & 121 & $\begin{array}{c}\text { AT0 NN1 VVD } \\
\text { AV0 }\end{array}$ & $\begin{array}{c}\text { The_AT0 tide_NN1 } \\
\text { ebbed_VVD } \\
\text { away_AV0. }\end{array}$ & $\begin{array}{l}\text { The_AT0 bullet_NN1 } \\
\text { hit_VVD home_AV0 . }\end{array}$ \\
\hline 5 & 85 & $\begin{array}{c}\text { AT0 NN1 VBZ } \\
\text { AJ0 }\end{array}$ & $\begin{array}{l}\text { A_AT0 drum_NN1 } \\
\text { is_VBZ noisy_AJ0 . }\end{array}$ & $\begin{array}{l}\text { The_AT0 tyre_NN1 } \\
\text { is_VBZ flat_AJ0. }\end{array}$ \\
\hline 6 & 84 & $\begin{array}{c}\text { PNP VBZ AV0 } \\
\text { AJ0 }\end{array}$ & $\begin{array}{c}\text { He_PNP ‘s_VBZ } \\
\text { very_AV0 dim_AJ0 }\end{array}$ & $\begin{array}{c}\text { It_PNP's_sVBZ } \\
\text { too_AV0 salty_AJ0 . }\end{array}$ \\
\hline 7 & 80 & $\begin{array}{l}\text { PNP VVD DPS } \\
\text { NN2 }\end{array}$ & $\begin{array}{c}\text { I_PNP sent_VVD } \\
\text { her_DPS } \\
\text { tapes_NN2. }\end{array}$ & $\begin{array}{l}\text { He_PNP wet_VVD } \\
\text { my_DPS pants_NN2 . }\end{array}$ \\
\hline 8 & 78 & $\begin{array}{l}\text { PNP VVB DPS } \\
\text { NN1 }\end{array}$ & $\begin{array}{l}\text { I_PNP like_VVB } \\
\text { my_DPS job_NN1. }\end{array}$ & $\begin{array}{l}\text { I_PNP miss_VVB } \\
\text { my_DPS dad_NN1 . }\end{array}$ \\
\hline 9 & 66 & $\begin{array}{c}\text { VVB AT0 NN1 } \\
\text { NN1 }\end{array}$ & $\begin{array}{c}\text { Put_VVB the_AT0 } \\
\text { book_NN1 } \\
\text { back_NN1. }\end{array}$ & $\begin{array}{c}\text { Take_VVB a_AT0 } \\
\text { heap_NN1 dump_NN1 . }\end{array}$ \\
\hline 10 & 64 & $\begin{array}{c}\text { AT0 NN1 VVZ } \\
\text { AV0 }\end{array}$ & $\begin{array}{c}\text { The_AT0 } \\
\text { wind_NN1 } \\
\text { blows_VVZ } \\
\text { hard_AV0 . }\end{array}$ & $\begin{array}{l}\text { The_AT0 road_NN1 } \\
\text { ends__VVZ here_AV0 . }\end{array}$ \\
\hline 11 & 59 & $\begin{array}{c}\text { AT0 NN1 VVZ } \\
\text { NN1 }\end{array}$ & $\begin{array}{c}\text { A_AT0 tree_NN1 } \\
\text { needs_VVZ } \\
\text { bark_NN1. }\end{array}$ & $\begin{array}{l}\text { The_AT0 sun_NN1 } \\
\text { emits_VVZ light_NN1 . }\end{array}$ \\
\hline 12 & 57 & $\begin{array}{c}\text { AT0 NN1 VBD } \\
\text { AJ0 }\end{array}$ & $\begin{array}{l}\text { The_AT0 bin_NN1 } \\
\text { was_VBD full_AJ0 }\end{array}$ & $\begin{array}{l}\text { The_AT0 sea_NN1 } \\
\text { was_VBD wild_AJ0 . }\end{array}$ \\
\hline 13 & 55 & $\begin{array}{c}\text { DT0 VBZ DPS } \\
\text { NN1 }\end{array}$ & $\begin{array}{l}\text { This_DT0 is_VBZ } \\
\text { my_DPS pen_NN1 }\end{array}$ & $\begin{array}{l}\text { This_DT0 is_VBZ } \\
\text { my_DPS toy_NN1 . }\end{array}$ \\
\hline 14 & 54 & $\begin{array}{c}\text { DT0 NN2 VBB } \\
\text { AJ0 }\end{array}$ & $\begin{array}{c}\text { All_DT0 men_NN2 } \\
\text { are_VBB } \\
\text { mortal_AJ0 } .\end{array}$ & $\begin{array}{l}\text { These_DT0 shirts_NN2 } \\
\text { are_VBB new_AJ0. }\end{array}$ \\
\hline
\end{tabular}


International scientific and practical conference

\begin{tabular}{|c|c|c|c|c|}
\hline 15 & 54 & $\begin{array}{l}\text { NP0 VVD AT0 } \\
\text { NN1 }\end{array}$ & $\begin{array}{c}\text { Eddie_NP0 } \\
\text { felt_VVD a_AT0 } \\
\text { shiver_NN1. }\end{array}$ & $\begin{array}{l}\text { Hugh_NP0 left_VVD } \\
\text { the_AT0 room_NN1. }\end{array}$ \\
\hline 16 & 53 & $\begin{array}{c}\text { DPS NN1 VBZ } \\
\text { AJ0 }\end{array}$ & $\begin{array}{l}\text { His_DPS fur_NN1 } \\
\text { is_VBZ white_AJ0 . }\end{array}$ & $\begin{array}{l}\text { Its_DPS trunk_NN1 } \\
\text { is_VBZ big_AJ0. }\end{array}$ \\
\hline 17 & 53 & $\begin{array}{l}\text { VVB AT0 AJ0 } \\
\text { NN1 }\end{array}$ & $\begin{array}{c}\text { Surf_VVB a_AT0 } \\
\text { Hawaiian_AJ0 } \\
\text { wave_NN1. }\end{array}$ & $\begin{array}{l}\text { Click_VVB the_AT0 } \\
\text { General_AJ0 TAB_NN1 }\end{array}$ \\
\hline 18 & 52 & $\begin{array}{c}\text { AT0 NN1 VVD } \\
\text { AVP }\end{array}$ & $\begin{array}{l}\text { The_AT0 } \\
\text { gamble_NN1 } \\
\text { paid_VVD } \\
\text { off_AVP. }\end{array}$ & $\begin{array}{l}\text { The_AT0 ground_NN1 } \\
\text { caved_VVD in_AVP. }\end{array}$ \\
\hline 19 & 52 & $\begin{array}{c}\text { AT0 NN2 VBB } \\
\text { AJ0 }\end{array}$ & $\begin{array}{c}\text { The_AT0 } \\
\text { rides_NN2 } \\
\text { are_VBB free_AJ0. }\end{array}$ & $\begin{array}{l}\text { The_AT0 ants_NN2 } \\
\text { are_VBB busy_AJ0 . }\end{array}$ \\
\hline 20 & 52 & $\begin{array}{c}\text { PNP VVZ PRP } \\
\text { NN1 }\end{array}$ & $\begin{array}{c}\text { He_PNP } \\
\text { suffers_VVZ } \\
\text { from_PRP } \\
\text { asthma_NN1. }\end{array}$ & $\begin{array}{c}\text { She_PNP sighs_VVZ } \\
\text { in_PRP agreement_NN1 } \\
\text {. }\end{array}$ \\
\hline
\end{tabular}

Якщо зменшити кількість категорій, нагадаю, тут для англійської мови було використано 62 граматичні категорії, то теоретично кількість моделей речень можна скоротити ще.

Для англійського тексту щоб автоматизувати зазначений процес, ми розробили аналогічну програму на мові Python, що створює список усіх моделей речень корпусу завдяки бібліотекам NLTK [7]. Відрізняється лише початкова частина коду:

with open('quword_en_4.txt', 'rt', encoding='utf-8') as f0:

with open('teg_text_en.txt', 'wt', encoding='utf-8') as f1: while True:

$$
\begin{aligned}
& \text { sentence }=\text { f0.readline }() \\
& \text { tokens }=\text { nltk.word_tokenize(sentence }) \\
& \text { tagged }=\text { nltk.pos_tag(tokens }) \\
& \text { for word, flag in tagged: } \\
& \mathrm{s} 2=(\text { '\%s_\%s' \% (word, flag) }) \\
& \operatorname{print}\left(\mathrm{s} 2, \text { file }=\mathrm{f} 1 \text {, end }={ }^{6}\right. \text { ') } \\
& \text { print (", file }=\mathrm{f} 1) \\
& \text { if not sentence: }
\end{aligned}
$$

Повторивши зазначений експеримент, ми отримали дещо інші данні через різницю в кількості граматичних категорій тегування, тут їх лише 36 [8]. Початкова кількість речень - 13000 , після тегування 
отримано 3536 моделей речень, що складає уже 27\%, найчастотніші 20 див.Табл. 7.

Історично найвпливовішими наборами тегів були ті, що використовувались для позначення американського корпусу Брауна та серії тегів, розроблених в Університеті Ланкастера, а потім Британського національного корпусу CLAWS5; CLAWS5 також називається набором тегів с5 Penn Treebank Tag. Набір тегів Penn Treebank - це спрощена версія набору тегів Brown, широко використовується в обчислювальних роботах для англійської мови. Загалом, набори тегів включають морфологічні відмінності певної мови, i тому безпосередньо не застосовуються до інших мов [2, 139-141].

Таблиця 7

Частотні моделі англійських речень на 4 слова виділені в автоматичному режимі

\begin{tabular}{|c|c|c|c|c|}
\hline № & $\begin{array}{l}\text { Кіль- } \\
\text { кість }\end{array}$ & Модель речення & \multicolumn{2}{|c|}{ Приклади вживання } \\
\hline 1 & 220 & $\begin{array}{c}\text { PRP_VBD_DT_NN } \\
-\end{array}$ & $\begin{array}{c}\text { I_PRP } \\
\text { got_VBD } \\
\text { the_DT } \\
\text { axe_NN._. }\end{array}$ & $\begin{array}{c}\text { It_PRP was_VBD a_DT } \\
\text { nova_NN !. }\end{array}$ \\
\hline 2 & 145 & $\begin{array}{c}\text { PRP_VBP_DT_NN } \\
-\end{array}$ & $\begin{array}{c}\text { I_PRP } \\
\text { need_VBP } \\
\text { a_DT vase_NN }\end{array}$ & $\begin{array}{c}\text { I_PRP am_VBP the_DT } \\
\text { winner_NN ! . }\end{array}$ \\
\hline 3 & 143 & 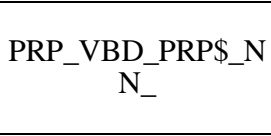 & $\begin{array}{c}\text { He_PRP } \\
\text { wet_VBD } \\
\text { my_PRP\$ } \\
\text { pants_NNS. }\end{array}$ & $\begin{array}{l}\text { I_PRP dropped_VBD } \\
\text { my_PRP\$ spoon_NN. }\end{array}$ \\
\hline 4 & 136 & DT_NN_VBZ_JJ_ & $\begin{array}{c}\text { A_DT } \\
\text { drum_NN } \\
\text { is_VBZ } \\
\text { noisy_JJ._. }\end{array}$ & $\begin{array}{l}\text { The_DT tyre_NN } \\
\text { is_VBZ flat_JJ ._. }\end{array}$ \\
\hline 5 & 126 & PRP_VBD_IN_NN_ & $\begin{array}{c}\text { They_PRP } \\
\text { went_VBD } \\
\text { by_IN ship_NN }\end{array}$ & $\begin{array}{l}\text { We_PRP woke_VBD } \\
\text { at_IN dawn_NN ... }\end{array}$ \\
\hline 6 & 124 & DT_NN_VBD_RB_ & $\begin{array}{l}\text { The_DT } \\
\text { table_NN } \\
\text { was_VBD } \\
\text { messy_RB... }\end{array}$ & $\begin{array}{c}\text { The_DT baby_NN } \\
\text { walks_VBD fast_RB ._ }\end{array}$ \\
\hline 7 & 119 & DT_NN_VBZ_RB_ & $\begin{array}{c}\text { The_DT } \\
\text { water_NN } \\
\text { is_VBZ off_RB }\end{array}$ & $\begin{array}{l}\text { The_DT job_NN } \\
\text { is_VBZ yours_RB ... }\end{array}$ \\
\hline 8 & 100 & $\begin{array}{c}\text { PRP_VBZ_DT_NN } \\
-\end{array}$ & $\begin{array}{l}\text { It_PRP 's_VBZ } \\
\text { a_DT duck_NN }\end{array}$ & $\begin{array}{c}\mathrm{He} \text { ePRP is_VBZ a_DT } \\
\text { parson_NN ... }\end{array}$ \\
\hline
\end{tabular}


International scientific and practical conference

\begin{tabular}{|c|c|c|c|c|}
\hline 9 & 100 & DT_NNS_VBP_JJ_ & $\begin{array}{l}\text { The_DT } \\
\text { rides_NNS } \\
\text { are_VBP } \\
\text { free_JJ... }\end{array}$ & $\begin{array}{l}\text { All_DT men_NNS } \\
\text { are_VBP mortal_JJ ... }\end{array}$ \\
\hline 10 & 100 & NNP_VBD_DT_NN & $\begin{array}{l}\text { Tommy_NNP } \\
\text { was_VBD } \\
\text { a_DT leaf_NN }\end{array}$ & $\begin{array}{l}\text { Pony_NNP had_VBD } \\
\text { no_DT idea_NN .- }\end{array}$ \\
\hline 11 & 98 & PRP_VBZ_RB_JJ_ & $\begin{array}{c}\text { It_PRP is_VBZ } \\
\text { very_RB } \\
\text { cute_JJ._. }\end{array}$ & $\begin{array}{c}\text { It_PRP 's_VBZ so_RB } \\
\text { unfair_JJ!_. }\end{array}$ \\
\hline 12 & 95 & $\begin{array}{c}\text { PRP_VBP_PRP\$_N } \\
\mathrm{N}_{-}\end{array}$ & $\begin{array}{c}\text { I_PRP let_VBP } \\
\text { her_PRPS } \\
\text { go_NN._. }\end{array}$ & $\begin{array}{l}\text { I_PRP like_VBP } \\
\text { my_PRP\$ job_NN ... }\end{array}$ \\
\hline 13 & 94 & $\begin{array}{c}\text { PRP_VBP_JJ_NNS } \\
-\end{array}$ & $\begin{array}{c}\text { I_PRP } \\
\text { see_VBP } \\
\text { many_JJ } \\
\text { cows_NNS._. }\end{array}$ & $\begin{array}{l}\text { I_PRP like_VBP fat_JJ } \\
\text { chicks_NNS ... }\end{array}$ \\
\hline 14 & 85 & $\begin{array}{c}\text { NNP_VBZ_DT_NN } \\
-\end{array}$ & $\begin{array}{l}\text { Sophie_NNP } \\
\text { knows_VBZ } \\
\text { a_DT lot_NN }\end{array}$ & $\begin{array}{l}\text { Kate_NNP has_VBZ } \\
\text { a_DT cousin_NN ... }\end{array}$ \\
\hline 15 & 83 & $\begin{array}{c}\text { DT_NN_VBZ_VBN } \\
-\end{array}$ & $\begin{array}{l}\text { The_DT } \\
\text { boat_NN } \\
\text { has_VBZ } \\
\text { sunk_VBN._. }\end{array}$ & $\begin{array}{l}\text { The_DT sky_NN } \\
\text { is_VBZ cloudy_VBN ._. }\end{array}$ \\
\hline 16 & 74 & DT_NN_VBZ_NN_ & $\begin{array}{c}\text { The_DT } \\
\text { knife_NN } \\
\text { is_VBZ } \\
\text { blunt_NN ._. }\end{array}$ & $\begin{array}{l}\text { The_DT soup_NN } \\
\text { needs_VBZ salt_NN . }\end{array}$ \\
\hline 17 & 71 & $\begin{array}{c}\text { DT_NN_VBZ_VBG } \\
-\end{array}$ & $\begin{array}{c}\text { A_DT } \\
\text { wolf_NN } \\
\text { is_VBZ } \\
\text { coming_VBG }\end{array}$ & $\begin{array}{c}\text { The_DT dog_NN } \\
\text { is_VBZ barking_VBG ._ }\end{array}$ \\
\hline 18 & 69 & DT_NN_IN_NN_ & $\begin{array}{l}\text { A_DT } \\
\text { type_NN of_IN } \\
\text { muffin_NN._. }\end{array}$ & $\begin{array}{l}\text { A_DT plaything_NN } \\
\text { of_IN fate_NN ._. }\end{array}$ \\
\hline 19 & 67 & DT_NN_VBD_JJ_ & $\begin{array}{l}\text { The_DT } \\
\text { pig_NN } \\
\text { went_VBD } \\
\text { wild_JJ ._. }\end{array}$ & $\begin{array}{l}\text { The_DT weather_NN } \\
\text { was_VBD bad_JJ. }\end{array}$ \\
\hline 20 & 65 & $\begin{array}{c}\text { PRP_VBD_PRP_N } \\
\mathrm{N}_{-}\end{array}$ & $\begin{array}{c}\text { He_PRP } \\
\text { taught_VBD } \\
\text { us_PRP } \\
\text { physics_NNS } \\
\text {._. }\end{array}$ & $\begin{array}{c}\text { It_PRP made_VBD } \\
\text { me_PRP speechless_NN } \\
\cdot-\cdot\end{array}$ \\
\hline
\end{tabular}


Порівнявши таблиці Табл. 6. та Табл. 7., бачимо, що хоча $\epsilon$ відмінність у кількості категорій, але загалом частотні моделі речень лишаються ті ж самі.

Враховуючи кількість моделей навіть для коротких речень у 4 слова, якісний машинний переклад на основі правил (Rule-based), що враховуватиме абсолютно всі лінгвістичні варіації, сьогодні досить складне завдання. Методика автоматичного виділення частотних моделей речень може бути застосована для створення якісних підручників іноземних мов.

\section{Література:}

1. Козоріз О. Порівняльний аналіз різнотематичних лінгвістичних корпусів. Актуальні питання гуманітарних наук. 2021. Вип. 35. Т. 3. C. 117-125. URL: http://www.aphn-journal.in.ua/archive/35_2021/part_3/ 18.pdf (accessed 1 July 2021).

2. Christopher D. Manning, Hinrich Schütze, 1999, Foundations of Statistical Natural Language Processing, $680 \mathrm{p}$.

3. AntConc Homepage. URL: http://www.laurenceanthony.net/software/ antconc/ (accessed 1 July 2021).

4. Corpus software and related tools. URL: http://ucrel.lancs.ac.uk/ tools.html (accessed 1 July 2021).

5. Free CLAWS web tagger. URL: http://ucrel-api.lancaster.ac.uk/ claws/free.html (accessed 1 July 2021).

6. Jieba. URL: https://github.com/fxsjy/jieba (accessed 1 July 2021).

7. NLTK. URL: http://www.nltk.org/ (accessed 1 July 2021).

8. Penn Treebank II Tags. URL: https://web.archive.org/web/ 2013 0517134339/http://bulba.sdsu.edu/jeanette/thesis/PennTags.html (accessed 1 July 2021).

9. UCREL CLAWS5 Tagset. URL: http://ucrel.lancs.ac.uk/ claws 5tags.html (accessed 1 July 2021).

10.汉语分词和词性自动标注. URL: http://corpus.zhonghuayuwen.org/ CpsWParser.aspx (accessed 1 July 2021).

11. QuWord. URL: https://www.quword.com/ (accessed 1 July 2021).

12. SegmentAnt. URL: https://www.laurenceanthony.net/software/ segmentant/ (accessed 1 July 2021). 